\title{
Analysis on Multidimensional Poverty Reduction of Industrial Structure Upgrading Based on Provincial Panel Data and Spatial Durbin Model
}

\author{
Zhengqi Gong ${ }^{1}$, Qingkai Kong ${ }^{1}$, Jian $\operatorname{Tan}^{2 *}$ \\ ${ }^{1}$ School of Economics, Guizhou University of Finance and Economics, Guiyang 550025, China \\ ${ }^{2}$ School of Business Administration, Guizhou University of Finance and Economics, Guiyang 550025, China \\ Corresponding Author Email: tanjian@mail.gufe.edu.cn
}

https://doi.org/10.18280/ijsdp.150806

Received: 10 June 2020

Accepted: 25 September 2020

\section{Keywords:}

multidimensional poverty (MDP), industrial structure upgrading (ISU), nonlinear effects, spatial spillover

\begin{abstract}
Industrial structure upgrading (ISU) has growth effect, siphon effect, and employment effect The three effects exert different impacts on multiple dimensions of poverty, namely, income, medical care, and education. To obtain the relationship between and size of these effects, this paper sets up a nonlinear analysis framework, and verifies the framework empirically based on the provincial panel data of China in 2003-2017, using the spatial Doberman model (SDM). The results show that: (1) Both MDP and ISU have spatial spillover effects; (2) Advanced ISU can effectively ease the income and medical poverties in adjacent provinces, and exert an inverted U-shaped impact on local education poverty; (3) Rational ISU has a U-shaped impact on local income poverty, an inverted U-shaped impact on local medical poverty, and no significant impact on education poverty.
\end{abstract}

\section{INTRODUCTION}

Poverty has always been a bottleneck in the progress of human society. At the end of 1978, the poverty-stricken population in China was 770 million. By the end of 2019, that number miraculously decreased by $66.8 \%$, leaving only 5.51 million impoverished in rural areas. It is expected that China will eradicate absolute poverty in 2020 . To improve the living standard and freedom through development, the focus of poverty alleviation will shift from the eradication of absolute poverty towards the mitigation of multidimensional poverty (MDP) [1], aiming to guarantee the food, clothing, compulsory education, basic medical care, and housing of the poor [2]. Apart from income, MDP covers the medical care, education, and living standard of residents [3].

Since the reform and opening-up, China's industrial structure has undergone great changes. The proportions of the three industries have changed from $27.7 \%: 47.7 \%: 24.6 \%$ to 7.2\%: 40.7\%: $52.2 \%$. The structural changes contribute immensely to the sustained and rapid economic development, which in turn affects poverty to a certain extent. During industrial structure upgrading (ISU), different industries alternately occupy a dominant position [4]. This raises several important questions: Can the dynamic evolution of the industrial structure impact poverty in different dimensions? Are there any difference in the impacts? What are the forms of the difference? What is the reason for the difference?

To answer the above questions, this paper designs a nonlinear analysis framework for the relationship between and size of the impacts of ISU on different dimensions of poverty. Based on the provincial panel data of China in 2003-2017, an empirical analysis was conducted to verify the established framework, with the aid of the spatial Durbin model (SDM). The research results shed new light on MDP reduction through ISU.

\section{LITERATURE REVIEW}

Since Amartya Sen treated poverty as the deprivation of capacities, poverty has gradually been regarded as a multidimensional concept, involving such dimensions as education, medical care, housing, job opportunities, and freedom. In other words, the poverty is not solely resulted from the low income, but also from the lack of abilities to get rid of poverty. The multidimensional poverty index (MPI) designed by the United Nations Development Programme (UNDP) contains the deprivations in health, education, and standard of living.

On the poverty reduction effect of ISU, most scholars defined poverty as income poverty. Their findings provide a reference for this research, although the definition differs from the concept of MDP. For example, Datt and Ravallion [5], and Thorbecke and Jung [6] investigated poverty in India and Indonesia, respectively, and found that the development of primary and tertiary industries effectively alleviates poverty, while the development of secondary industry has a limited effect on poverty alleviation. Chen and Ravallion [7] empirically analyzed China's data from 1980 to 2001, and learned that agriculture can alleviate rural poverty more effectively than secondary and tertiary industries.

Chinese researchers have basically followed the foreign methods to explore the poverty reduction effect of ISU. For instance, Li et al. [8] examined the poverty in China from 2000 to 2008 , and discovered that the primary industry has poorer poverty alleviation effect than second and tertiary industries. Zhang and Ye [9] argued that, with continued economic growth, the contributions of the three industries to poverty alleviation are changing, and the secondary industry now contributes greater to poverty alleviation than the other two industries. 
The above studies demonstrate that different industries have different effects on poverty alleviation. But their conclusions are not consistent, as they deal with different regions in different periods. Then, what is the reason for this difference? Using a mathematical model, Loayza and Raddatz [10] proved labor intensity as a key determinant of the poverty reduction effect of an industry, and concluded that the primary industry has the best mitigation effect on poverty, followed by second and tertiary industries.

The existing literature has shown that different industries have different poverty reduction effects in different periods, and explained the source of this difference to a certain extent. However, the following points need to be further improved: First, the previous research paradigm, which analyzes the poverty reduction effects of the three industries separately, assumes that the three industries develop independently of each other, and ignores the dynamic adjustment of ISU and the interaction between industries; Second, the current research on poverty only tackles the single dimension of income poverty, without considering MDP; Third, the relevant studies mainly adopt time series data, cross-sectional data, and panel data, failing to handle spatial data, and thus neglect the spatial spillover effect between individuals.

\section{PRELIMINARIES}

\subsection{Two dimensions and three effects of ISU}

Advancement and rationalization are two key dimensions of ISU. The advanced ISU mainly measures whether the output of the secondary and tertiary industries accounts for a greater proportion in gross national product (GNP), while the rational ISU mainly reflects whether the coupling between input and output of production factors deepens. The two dimensions of ISU bring three effects on resident life: growth effect, employment effect, and siphon effect.

(1) Growth effect

The difference in factor returns between sectors drives the inter-industry flow of production factors. The secondary and tertiary industries tend to have a high production efficiency and provide rich returns for production factors. Under market configuration, production factors always move toward these two sectors, and in turn promote ISU. In this way, ISU not only rationalizes the return of high-quality production factors, but also improves the mean productivity of the whole society. The fast economic growth that ensues will have a positive impact on poverty reduction.

(2) Siphon effect

In general, the sectors that develop rapidly attract the best resources. In the same period, the society has a limited number of resources. Different sectors must compete for the limited resources. The sectors failing to access high-quality resources will develop at a slow pace. This phenomenon is called the siphon effect.

(3) Employment effect

The growth effect and siphon effect are produced simultaneously in advanced ISU and rational ISU. From the rational ISU alone, the sectors that develop rapidly create a huge number of jobs for the impoverished, improving their standard of living.

\subsection{Actions of the three effects on MDP}

In the following analysis, the MDP was examined in three dimensions: income, medical care, and education [11]. This approach is superior to the Alkire-Foster MDP adopted by the UNDP [12]. By decomposing MDP into three dimensions, it is possible to discover the heterogeneity of poverty in different dimensions, and the differential impact of ISU to poverty in different dimensions [13]. For example, this research learns that rational ISU has a U-shaped impact on income poverty, an inverted-U-shaped impact on medical poverty, and no significant impact on education poverty.

Although poverty is a holistic concept, the bucket effect in poverty alleviation is worthy of attention [14]. The neglection of any dimension will hinder the completion of poverty alleviation [15]. If the poverty alleviation is measured by a comprehensive index, it is impossible to identify the difference between poverty in different dimensions, which impedes detailed research.

The circular cumulative causation, proposed by Gunnar Myrdal [16], suggests that economic development has echo effect and diffusion effect. Similarly, the growth effect, employment effect, and siphon effect of ISU all exert a certain impact on poverty. Since the three effects alternately occupy a dominant position, the ISU brings differential impacts on poverty in different dimensions in different periods.

\subsubsection{Employment effect and income poverty}

The rational ISU drives the employees to transfer from the primary industry to the secondary and tertiary industries. In the latter industries, most sectors are capital or technologyintensive, calling for workers of high skills. As a result, some workers cannot complete the transfer, leading to structural unemployment in the short term. Then, job vacancies and unemployment will coexist, and the unemployed will face a growth in income poverty. In the long run, however, the employment effect will come into play. The high-quality workers whose skills meet job requirements will be well liked. After acquiring job skills through training, the workers can find a job and return to work. To sum up, with the rational ISU, the income poverty will first intensify and then ease, exhibiting an inverted-U-shaped trend.

\subsubsection{Siphon effect and medical/education poverty}

Like income, medical care and education are indicators of the MDP of residents. The income poverty is not greatly affected by the rise or fall of a particular sector. By contrast, medical and education poverties directly hinge on medical and education sectors, respectively. In China, medical and education sectors are public industries with stable rate of return. Neither has excessive attraction to production factors. In the beginning of ISU, medical and education sectors will develop slowly, due to the siphon effect, and medical and education poverties will increase.

\subsubsection{Growth effect and income/medical/education poverty}

With the continuous ISU, fast-growing sectors create and accumulate more and more wealth, thanks to their high utilization rate of production factors. The wealth creation and accumulation help to elevate resident income and alleviate income poverty. Meanwhile, the capital and innovative technologies accumulated in these sectors will spread to medical and education sectors. That is, the growth effect will act on medical and educational undertakings, alleviating medical and education poverties.

Throughout the ISU, the siphon effect and the growth effect alternately occupy a dominant position. In the initial phase, the 
siphon effect dominates the ISU, causing medical and education poverties to intensify; after the ISU enters the mature phase, medical and education sectors are mainly affected by the growth effect, and medical and education poverties will ease. As a result, medical and education poverties follow an inverted-U-shaped trend with the progress of the ISU.

To sum up, it is hypothesized that ISU has an inverted-Ushaped impact on income poverty, medical poverty, and education poverty. The action mechanism of ISU on MDP alleviation is illustrated in Figure 1.

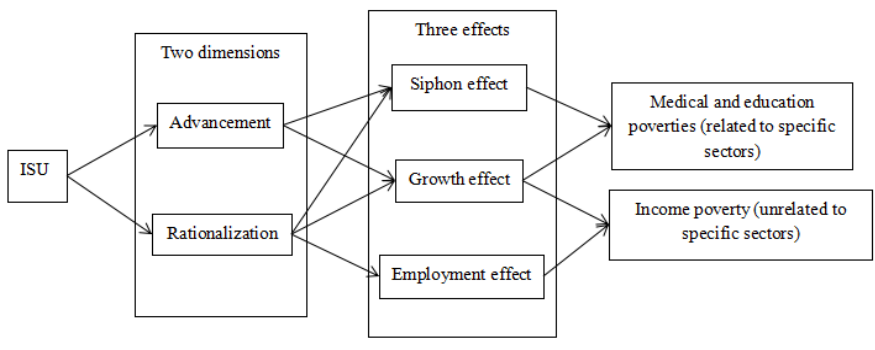

Figure 1. The action mechanism of ISU on MDP alleviation

\section{METHODOLOGY}

\subsection{Spatial econometric model}

\subsubsection{Basic form}

Capital and technology are two fast flowing production factors with few restrictions. As China continues to relax the limitations of the household registration system, the circulation of labor is increasingly free between regions. As a result, the ISU can radiate a wider scope, and affect the poverty in surrounding areas [17]. To fully consider the spillover effect between individuals in space, the SDM was adopted for empirical analysis:

$$
\mathrm{Y}_{\mathrm{it}}=\rho \mathrm{W}_{\mathrm{i}} \mathrm{Y}_{\mathrm{it}}+\beta \mathrm{X}_{\mathrm{it}}+\theta \mathrm{W}_{\mathrm{i}} \mathrm{X}_{\mathrm{it}}+\mu_{\mathrm{i}}+\gamma_{\mathrm{t}}+\varepsilon_{\mathrm{it}}, \varepsilon_{i t} \sim N\left(0, \sigma^{2} I_{n}\right)
$$

where, $Y_{i t}$ is the explained variable; $X_{i t}$ is the explanatory variable; $\mathrm{W}_{\mathrm{i}}$ is the spatial weight matrix; $W_{i} Y_{i t}$ is the spatial lag of the explained variable; $W_{i} X_{i t}$ is the spatial lag of the explanatory variable; $\mu_{i}$ is the spatial fixed effect; $\gamma_{t}$ is the time fixed effect; $\varepsilon_{i t}$ is the error term ( $i$ is region; $t$ is year); $\rho, \beta$, and $\theta$ are the parameters to be estimated. If $\rho$ is significantly different from 0 , the coefficient $\beta$ of the explanatory variable cannot represent all the impact on the explained variable. In this case, the total effect should be divided into direct and indirect effects through partial differentiation. Note that region refers to provincial administrative region in China. For simplicity, the term provincial administrative region will be referred to as province in the following analysis.

\subsubsection{Spatial correlation test}

The feasibility of the spatial econometric model depends on the spatial correlation between variables. The spatial correlation was tested by the Moran's I index:

$$
I=\frac{\sum_{i=1}^{n} \sum_{j=1}^{n} \omega_{i j}\left(x_{i}-\bar{x}\right)\left(x_{j}-\bar{x}\right)}{S^{2} \sum_{i=1}^{n} \sum_{j=1}^{n} \omega_{i j}}
$$

where, $S^{2}$ is the sample variance; $\omega_{i j}$ is the element $(i, j)$ in the given spatial weight index. The Moran's I falls in the range of $(-1,1)$. If the index is greater than 0 , the variables have positive spatial correlation; if the index is smaller than 0 , the variables have negative spatial correlation; if the index is not significantly different from 0 , the variables have no spatial correlation.

\subsubsection{Spatial weight matrix}

The spatial weight matrix mirrors spatial correlation. It can reflect the interaction between variables at different spatial positions. To test the robustness of empirical results, the regression results of three spatial weight matrices were displayed together: adjacency matrix, economic matrix, and nested matrix. Table 1 provides the specific settings of the matrices.

\begin{tabular}{|c|c|c|c|c|}
\hline Name & Code & Meaning & Formula & Explanation \\
\hline $\begin{array}{l}\text { Adjacency } \\
\text { matrix }\end{array}$ & W1 & Adjacency between provinces & $\omega_{i j}=\left\{\begin{array}{l}0 \\
1\end{array}\right.$ & $\begin{array}{c}0 \text { means provinces } i \text { and } \mathrm{j} \text { are not adjacent; } 1 \text { means } i \text { and } j \text { are } \\
\text { adjacent. }\end{array}$ \\
\hline $\begin{array}{l}\text { Economic } \\
\text { matrix }\end{array}$ & W2 & Economic gap between provinces & $\omega_{i j}=\frac{1}{\left|P_{i}-P_{j}\right|}$ & $\begin{array}{l}P_{i} \text { and } P_{j} \text { mean the mean per-capita gross domestic product } \\
\text { (GDP) of provinces } i \text { and } j \text { in the sample period, respectively. }\end{array}$ \\
\hline Nested matrix & W3 & $\begin{array}{l}\text { Superposition of adjacency and } \\
\text { economic gap }\end{array}$ & $\mathrm{W} 1 * \mathrm{~W} 2$ & $\begin{array}{c}\text { W3 is the product of adjacency matrix and economic matrix, } \\
\text { with diagonal elements being zeros. }\end{array}$ \\
\hline
\end{tabular}

Table 1. The settings of spatial weight matrices

Note: In the 0-1 matrix, the island province Hainan is treated as adjacent to Guangdong, its nearest "neighbor"; otherwise, the isolated province will cause difficulty to data processing in Stata.

\subsection{Index explanation and data sources}

\subsubsection{Index explanation}

To verify the MDP reduction effect of ISU, this paper takes income poverty, education poverty, and medical poverty as the explained variables, selects advanced ISU and rational ISU as the core explanatory variables, and adds a series of control variables. The indices are explained as follows:

(1) Explained variables

The explained variable of this research is MDP. Drawing on Fu Peng's strategy [18], income poverty was measured by the
Engel coefficient of each province, medical poverty was measured by the reciprocal of the number of health technicians per 1,000 people in each province, and education poverty was measured by the number of the illiterate above 15 as a proportion in the total population in each province. These three metrics are positively correlated with the degree of poverty.

(2) Core explanatory variables

The ISU was measured by advanced ISU and rational ISU. The advanced ISU was calculated by [19]:

$$
H I S=y_{1} * 1+y_{2} * 2+y_{3} * 3,1 \leq H I S \leq 3
$$


where, $y_{i}$ is the output of an industry as a proportion of GDP. The HIS value is positively correlated with the level of advanced ISU.

The rational ISU was measured by structural deviation [20]. To facilitate the comparison with HIS, the opposite number of the metric was taken:

$$
R I S=-\sum_{i=1}^{n}\left|\frac{Y_{i} / L_{i}}{Y / L}-1\right|
$$

where, $Y_{i}$ is the output of an industry; $L_{i}$ is the number of employees of an industry. The RIS value is positively correlated with the level of rational ISU.

(3) Control variables

Besides the ISU, many other factors influence the MDP. After sorting out the relevant literature, this paper selects the following control variables: economic development, measured by the per-capita GDP of each province; opening-up, measured by the import-export volume as a proportion of GDP of each province; urbanization, measured by the urban population as a proportion of the total population of each province; urban-rural income gap, measured by the per-capita income ratio between urban and rural residents [21].

\subsubsection{Data sources}

The provincial panel data in 2003-2017 of China were adopted for the empirical analysis. The data on Tibet were removed, as many of its entries are missing. The data were collected from China Statistical Yearbooks, China Civil Affairs Statistical Yearbooks, China Population \& Employment Statistical Yearbooks, as well as the statistical yearbooks of each province. The descriptive statistics are shown in Table 2.

Table 2. The descriptive statistics on the variables

\begin{tabular}{|c|c|c|c|c|c|c|}
\hline Type & Name & Sample size & Mean & Standard deviation & Minimum & Maximum \\
\hline \multirow{3}{*}{ Explained variables } & Income poverty (POI) & 450 & 0.371 & 0.067 & 0.202 & 0.554 \\
\hline & Medical poverty (POM) & 450 & 0.228 & 0.082 & 0.049 & 0.510 \\
\hline & Education poverty (POE) & 450 & 0.072 & 0.045 & 0.012 & 0.241 \\
\hline \multirow{2}{*}{ Core explanatory variables } & Advanced ISU (HIS) & 450 & 2.315 & 0.125 & 2.070 & 2.802 \\
\hline & Rational ISU (RIS) & 450 & -2.138 & 0.982 & -8.214 & -0.860 \\
\hline \multirow{4}{*}{ Control variables } & Economic development (PGDP) & 450 & 2.560 & 1.691 & 0.348 & 8.855 \\
\hline & Opening-up (OPEN) & 450 & 0.296 & 0.386 & 0.007 & 1.777 \\
\hline & Urbanization (URB) & 450 & 0.506 & 0.147 & 0.248 & 0.896 \\
\hline & Urban-rural income gap (GAP) & 450 & 2.867 & 0.551 & 1.755 & 4.759 \\
\hline
\end{tabular}

\section{EMPIRICAL RESULTS AND ANALYSIS}

\subsection{Stationarity test}

To avoid false regression, the Levin-Lin-Chu method was adopted to test the stationarity of each variable. To balance heteroscedasticity, the logarithm of each variable was taken. From the test results in Table 3, it can be seen that the null hypothesis was rejected for each variable at the $5 \%$ significance level, indicating that the panel data are stable.

Table 3. The results of stationarity test

\begin{tabular}{|c|c|c|c|}
\hline Name of variable & Adjusted t value & p value & Result \\
\hline $\ln \mathrm{POI}$ & -5.074 & 0.000 & Stable \\
\hline $\operatorname{lnPOM}$ & -5.111 & 0.000 & Stable \\
\hline $\ln \mathrm{POE}$ & -2.776 & 0.003 & Stable \\
\hline $\operatorname{lnHIS}$ & -2.871 & 0.002 & Stable \\
\hline $\ln$ RIS & -4.476 & 0.000 & Stable \\
\hline $\ln$ PGDP & -3.863 & 0.000 & Stable \\
\hline $\operatorname{lnOPEN}$ & -2.642 & 0.004 & Stable \\
\hline $\ln U R B$ & -2.485 & 0.007 & Stable \\
\hline $\operatorname{lnGAP}$ & -3.552 & 0.000 & Stable \\
\hline
\end{tabular}

\subsection{Spatial correlation test}

Using the Moran's I index, the spatial correlation of income poverty, medical poverty, education poverty, advanced ISU, and rational ISU were checked year by year, using the adjacency matrix. The test results are presented in Table 4.

\subsection{Effect decomposition}

For the lack of space, the relevant regression results are not presented. It can be seen that the empirical results based on different matrices were highly consistent, and strongly reliable. For readability, the following analysis will focus on the results obtained based on the adjacency matrix, unless there are large discrepancies.

\subsection{Analysis on income poverty}

As shown in Table 5, lnHIS did not have a significant direct effect, reflecting the poor alleviation effect of advanced ISU on local income poverty. The coefficient of indirect effect was -2.670. The large coefficient and high significance indicate that, every $1 \%$ growth in advanced ISU can lower the income poverty in adjacent regions by $2.67 \%$. In the sample period, the growth effect of advanced ISU effectively mitigated the income poverty in adjacent regions. The high production efficiency of secondary and tertiary industries created lots of wealth for the society. With the increase in social wealth, the government could provide more transfer payment to the poor, which indirectly pushes up their income [22].

The direct effect coefficient of $\operatorname{lnRIS}{ }^{\wedge} 2$ was 0.048 , and the significance level was $10 \%$. This means the rational ISU exerts a U-shaped impact on income poverty. In other words, the growing level of rational ISU makes the income poverty of residents decrease first and then increase. This trend goes against our hypothesis. A possible reason is as follows: In the early phase of ISU, most newly created jobs do not require high skills. These jobs can absorb much of the surplus labor in rural areas, and relieve their income poverty [23]. Once these jobs are saturated, the job market is dominated by capital and technology-intensive enterprises. The remaining jobs raise high requirements on job skills. This brings some structural unemployment, which exacerbates income poverty. 
According to the theoretical results, the poverty increase induced by structural unemployment will be gradually eased by the improvement of worker skills. Thus, the U-shaped impact of rational ISU has an insignificant indirect effect.

Among the control variables, urban-rural income gap had the most significant impact, with a direct effect coefficient of 0.182 and an indirect effect coefficient of 0.408 . This means every $1 \%$ increase in urban-rural income gap will push up the income poverty by $0.182 \%$ in the local province and $0.408 \%$ in adjacent provinces. Economic development had an insignificant direct effect, but a significantly negative indirect effect. Therefore, economic development cannot mitigate the income poverty in the local province, but ease that in adjacent provinces to a certain extent [24].

Table 4. The results of spatial correlation test

\begin{tabular}{|c|c|c|c|c|c|}
\hline Year & Income poverty & Medical poverty & Education poverty & Advanced ISU & Rational ISU \\
\hline 2003 & $0.491 * * *(0.122)$ & $0.401 * * *(0.121)$ & $0.201 * *(0.122)$ & $0.051(0.111)$ & $0.331 * * *(0.100)$ \\
\hline 2004 & $0.440 * * *(0.122)$ & $0.388 * * *(0.121)$ & $0.278 * * *(0.122)$ & $0.044(0.110)$ & $0.341 * * *(0.100)$ \\
\hline 2005 & $0.461 * * *(0.121)$ & $0.404 * * *(0.120)$ & $0.344 * * *(0.122)$ & $0.077(0.109)$ & $0.398 * * *(0.110)$ \\
\hline 2006 & $0.531 * * *(0.122)$ & $0.367 * * *(0.121)$ & $0.276 * * *(0.121)$ & $0.086(0.107)$ & $0.427 * * *(0.112)$ \\
\hline 2007 & $0.544 * * *(0.122)$ & $0.414 * * *(0.120)$ & $0.191 * *(0.122)$ & $0.096(0.107)$ & $0.416 * * *(0.113)$ \\
\hline 2008 & $0.547 * * *(0.122)$ & $0.388 * * *(0.120)$ & $0.223 * *(0.121)$ & $0.112 *(0.108)$ & $0.464 * * *(0.116)$ \\
\hline 2009 & $0.504 * * *(0.122)$ & $0.355 * * *(0.120)$ & $0.197 * *(0.121)$ & $0.130 *(0.108)$ & $0.399 * * *(0.119)$ \\
\hline 2010 & $0.518 * * *(0.122)$ & $0.370 * * *(0.120)$ & $0.227 * *(0.120)$ & $0.179 * *(0.110)$ & $0.510 * * *(0.120)$ \\
\hline 2011 & $0.466 * * *(0.120)$ & $0.360 * * *(0.118)$ & $0.308 * * *(0.121)$ & $0.179 * *(0.109)$ & $0.453 * * *(0.121)$ \\
\hline 2012 & $0.440 * * *(0.120)$ & $0.332 * * *(0.118)$ & $0.285 * * *(0.119)$ & $0.191 * *(0.110)$ & $0.454 * * *(0.122)$ \\
\hline 2013 & $0.189 * *(0.120)$ & $0.260 * * *(0.118)$ & $0.275 * * *(0.116)$ & $0.179 * *(0.110)$ & $0.476 * * *(0.122)$ \\
\hline 2014 & $0.376 * * *(0.123)$ & $0.237 * * *(0.118)$ & $0.276 * * *(0.118)$ & $0.183 * *(0.109)$ & $0.473 * * *(0.123)$ \\
\hline 2015 & $0.395 * * *(0.122)$ & $0.182 * *(0.116)$ & $0.306 * * *(0.116)$ & $0.165 * *(0.111)$ & $0.474 * * *(0.124)$ \\
\hline 2016 & $0.348 * * *(0.121)$ & $0.168 * *(0.117)$ & $0.279 * * *(0.118)$ & $0.183 * *(0.112)$ & $0.461 * * *(0.124)$ \\
\hline 2017 & $0.322 * * *(0.121)$ & $0.177 * *(0.116)$ & $0.262 * * *(0.122)$ & $0.208 * *(0.111)$ & $0.458 * * *(0.124)$ \\
\hline
\end{tabular}

Note: The bracketed values are standard deviations; the variables marked with $*, * *$, and $* * *$ are significant at the significance levels of $10 \%, 5 \%$, and $1 \%$, respectively. The same below.

Table 5. The decomposition of effects on income poverty

\begin{tabular}{|c|c|c|c|c|}
\hline Variables & Decomposed effects & Adjacency matrix (W1) & Economic matrix (W2) & Nested matrix (W3) \\
\hline \multirow{3}{*}{$\operatorname{lnHIS}$} & Direct effect & $-0.360(0.249)$ & $-0.487(0.256)$ & $-0.201(0.253)$ \\
\hline & Indirect effect & $-2.670 * * *(0.401)$ & $-1.380 * *(0.451)$ & $-2.720 * * *(0.459)$ \\
\hline & Total effect & $-3.030 * * *(0.437)$ & $-1.870 * * *(0.511)$ & $-2.920 * * *(0.473)$ \\
\hline \multirow{3}{*}{$\ln \mathrm{RIS}$} & Direct effect & $0.154 * * *(0.045)$ & $0.146 * *(0.048)$ & $0.184 * * *(0.043)$ \\
\hline & Indirect effect & $0.088(0.101)$ & $-0.185(0.137)$ & $0.320(0.180)$ \\
\hline & Total effect & $0.242 *(0.100)$ & $-0.039(0.165)$ & $0.504 * *(0.186)$ \\
\hline \multirow{3}{*}{$\ln \operatorname{RIS}^{\wedge} 2$} & Direct effect & $0.048 *(0.021)$ & $0.067 * * *(0.021)$ & $0.083 * * *(0.020)$ \\
\hline & Indirect effect & $0.027(0.043)$ & $-0.037(0.053)$ & $0.140(0.086)$ \\
\hline & Total effect & $0.075(0.042)$ & $0.030(0.063)$ & $0.223 *(0.089)$ \\
\hline \multirow{3}{*}{$\operatorname{lnPGDP}$} & Direct effect & $-0.014(0.030)$ & $-0.036(0.034)$ & $-0.039(0.030)$ \\
\hline & Indirect effect & $-0.092 *(0.040)$ & $-0.091 *(0.044)$ & $-0.180 * *(0.061)$ \\
\hline & Total effect & $-0.105 * * *(0.028)$ & $-0.127 * *(0.039)$ & $-0.218 * * *(0.057)$ \\
\hline \multirow{3}{*}{$\operatorname{lnOPEN}$} & Direct effect & $0.005(0.009)$ & $0.022 *(0.010)$ & $-0.001(0.009)$ \\
\hline & Indirect effect & $0.004(0.021)$ & $0.032(0.026)$ & $0.045(0.023)$ \\
\hline & Total effect & $0.009(0.023)$ & $0.054(0.028)$ & $0.045(0.027)$ \\
\hline \multirow{3}{*}{$\ln U R B$} & Direct effect & $0.068(0.047)$ & $0.040(0.047)$ & $-0.001(0.044)$ \\
\hline & Indirect effect & $-0.068(0.119)$ & $0.120(0.151)$ & $0.581 *(0.257)$ \\
\hline & Total effect & $-0.001(0.122)$ & $0.160(0.176)$ & $0.580 *(0.270)$ \\
\hline \multirow{3}{*}{$\operatorname{lnGAP}$} & Direct effect & $0.182 *(0.072)$ & $0.267 * * *(0.072)$ & $0.180 *(0.076)$ \\
\hline & Indirect effect & $0.408^{* * *}(0.103)$ & $0.448 * *(0.147)$ & $0.697 * * *(0.144)$ \\
\hline & Total effect & $0.590 * * *(0.102)$ & $0.716^{* * *}(0.164)$ & $0.877 * * *(0.164)$ \\
\hline
\end{tabular}

\subsection{Analysis on medical poverty}

As shown in Table 6, the advanced ISU did not have a significant direct effect, indicating that advanced ISU cannot effectively alleviate the local medical poverty. The indirect effect coefficient was -1.800 , and significant at the $1 \%$ level. Hence, every $1 \%$ growth of advanced ISU can lower the medical poverty in adjacent provinces by $1.8 \%$.

$\operatorname{lnRIS}{ }^{\wedge} 2$ exhibited a significant direct effect, with a coefficient of -0.085 . Thus, the medical poverty varied in inverted-U-shape with the continued growth in rational ISU. This trend agrees with our hypothesis: medical poverty intensifies and then eases, with the rising rational ISU. In the initial phase of ISU, lots of resources flow into the fast- developing sectors like financial industry and consumer service industry. The siphon effect slows down the development of medical and health services, and intensifies the medical poverty. Further advancement of ISU gives play to the growth effect. The early-starting industries indirectly propel the medical industry. Meanwhile, the government has accumulated a large amount of fiscal revenue to support the improvement of the medical insurance system. The spatial spillover coefficient of rational ISU was -0.222 , that is, each $1 \%$ growth of rational ISU can reduce the medical poverty by $0.222 \%$ in adjacent provinces. This is attributable to the wide radiation of medical resources: many residents choose to see a doctor in another province.

As for the control variables, the opening-up helps to 
alleviate the medical poverty in the local province, and exerts an insignificant indirect effect. Urbanization directly promotes the alleviation of local medical poverty, but insignificantly affects the medical poverty in other provinces. The total effects of urbanization under the three matrices were -0.226 , 0.533 and -0.807 , respectively. The effect was not significant under W1. Thus, the effect of urbanization varies with the mode of spatial connections. The urban-rural income gap had significantly positive direct, indirect, and total effects, suggesting that a large urban-rural income gap will intensify the medical poverty in the local province and the adjacent provinces [25].

Table 6. The decomposition of effects on medical poverty

\begin{tabular}{|c|c|c|c|c|}
\hline Variables & Decomposed effects & Adjacency matrix (W1) & Economic matrix (W2) & Nested matrix (W3) \\
\hline \multirow{3}{*}{$\operatorname{lnHIS}$} & Direct effect & $0.252(0.265)$ & $0.333(0.281)$ & $0.308(0.296)$ \\
\hline & Indirect effect & $-1.800 * * *(0.504)$ & $-2.000 * * *(0.359)$ & $-2.280 * * *(0.437)$ \\
\hline & Total effect & $-1.550 * *(0.499)$ & $-1.670 * * *(0.345)$ & $-1.980 * * *(0.433)$ \\
\hline \multirow{3}{*}{$\ln$ RIS } & Direct effect & $-0.179 * * *(0.034)$ & $-0.126 * * *(0.035)$ & $-0.143 * * *(0.036)$ \\
\hline & Indirect effect & $-0.222 *(0.111)$ & $-0.221 * *(0.082)$ & $-0.498 * *(0.160)$ \\
\hline & Total effect & $-0.401 * *(0.125)$ & $-0.347 * * *(0.090)$ & $-0.641 * * *(0.164)$ \\
\hline \multirow{3}{*}{$\ln \mathrm{RIS}^{\wedge} 2$} & Direct effect & $-0.085 * * *(0.013)$ & $-0.048 * * *(0.015)$ & $-0.056 * * *(0.015)$ \\
\hline & Indirect effect & $0.018(0.040)$ & $-0.033(0.027)$ & $-0.102(0.067)$ \\
\hline & Total effect & $-0.067(0.043)$ & $-0.081 * *(0.031)$ & $-0.158 *(0.071)$ \\
\hline \multirow{3}{*}{$\ln P G D P$} & Direct effect & $-0.279 * * *(0.030)$ & $-0.077(0.041)$ & $-0.235^{* * *}(0.034)$ \\
\hline & Indirect effect & $0.107 *(0.049)$ & $-0.028(0.049)$ & $0.196 *(0.083)$ \\
\hline & Total effect & $-0.172 * * *(0.043)$ & $-0.105^{* *}(0.036)$ & $0.039(0.080)$ \\
\hline \multirow{3}{*}{$\operatorname{lnOPEN}$} & Direct effect & $-0.025 *(0.011)$ & $-0.046^{* * *}(0.011)$ & $-0.043 * * *(0.012)$ \\
\hline & Indirect effect & $-0.033(0.031)$ & $0.107 * * *(0.022)$ & $0.020(0.029)$ \\
\hline & Total effect & $-0.058(0.035)$ & $0.061 * *(0.023)$ & $-0.024(0.032)$ \\
\hline \multirow{3}{*}{$\ln U R B$} & Direct effect & $-0.235 * * *(0.045)$ & $-0.219 * * *(0.046)$ & $-0.289 * * *(0.046)$ \\
\hline & Indirect effect & $0.009(0.138)$ & $-0.313^{* *}(0.109)$ & $-0.518(0.276)$ \\
\hline & Total effect & $-0.226(0.148)$ & $-0.533 * * *(0.124)$ & $-0.807 * *(0.284)$ \\
\hline \multirow{3}{*}{$\operatorname{lnGAP}$} & Direct effect & $0.238 * * *(0.067)$ & $0.255^{* * *}(0.073)$ & $0.272 * * *(0.074)$ \\
\hline & Indirect effect & $0.818^{* * *}(0.118)$ & $0.645^{* * *}(0.117)$ & $0.322 *(0.147)$ \\
\hline & Total effect & $1.060 * * *(0.125)$ & $0.899 * * *(0.106)$ & $0.594 * * *(0.148)$ \\
\hline
\end{tabular}

Table 7. The decomposition of effects on education poverty

\begin{tabular}{|c|c|c|c|c|}
\hline Variables & Decomposed effects & Adjacency matrix (W1) & Economic matrix (W2) & Nested matrix (W3) \\
\hline \multirow{3}{*}{$\operatorname{lnHIS}$} & Direct effect & $24.600 * *(7.700)$ & $22.000^{* *}(7.541)$ & $5.110^{* * *}(1.548)$ \\
\hline & Indirect effect & $42.100(26.853)$ & $20.900(16.094)$ & $-3.780(8.184)$ \\
\hline & Total effect & $66.700 *(29.384)$ & $42.900 * *(16.294)$ & $1.340(8.927)$ \\
\hline \multirow{3}{*}{$\operatorname{lnHIS}{ }^{\wedge} 2$} & Direct effect & $-14.000 * *(4.626)$ & $-12.100 * *(4.552)$ & $-2.260 *(0.938)$ \\
\hline & Indirect effect & $-21.900(15.870)$ & $-10.200(9.356)$ & $5.290(5.099)$ \\
\hline & Total effect & $-35.800 *(17.239)$ & $-22.200 *(9.406)$ & $3.030(5.601)$ \\
\hline \multirow{3}{*}{$\ln R I S$} & Direct effect & $-0.065(0.067)$ & $0.033(0.073)$ & $-0.029(0.061)$ \\
\hline & Indirect effect & $-0.859(0.302)$ & $0.154(0.261)$ & $-0.211(0.250)$ \\
\hline & Total effect & $-0.151(0.340)$ & $0.187(0.310)$ & $-0.240(0.269)$ \\
\hline \multirow{3}{*}{$\ln P G D P$} & Direct effect & $-0.408 * * *(0.085)$ & $-0.187 *(0.087)$ & $-0.078(0.075)$ \\
\hline & Indirect effect & $-0.396 * *(0.143)$ & $-0.875 * * *(0.141)$ & $-0.853^{* *}(0.286)$ \\
\hline & Total effect & $-0.805 * * *(0.128)$ & $-1.060 * * *(0.136)$ & $-0.930 * *(0.293)$ \\
\hline \multirow{3}{*}{$\operatorname{lnOPEN}$} & Direct effect & $-0.009(0.027)$ & $-0.068 * *(0.026)$ & $-0.039(0.026)$ \\
\hline & Indirect effect & $0.141(0.095)$ & $0.086(0.081)$ & $0.180 *(0.086)$ \\
\hline & Total effect & $0.133(0.108)$ & $0.018(0.093)$ & $0.141(0.095)$ \\
\hline \multirow{3}{*}{$\ln U R B$} & Direct effect & $0.023(0.110)$ & $0.176(0.109)$ & $0.088(0.103)$ \\
\hline & Indirect effect & $-0.567(0.381)$ & $0.130(0.400)$ & $-0.294(0.971)$ \\
\hline & Total effect & $-0.544(0.427)$ & $0.306(0.462)$ & $-0.206(1.008)$ \\
\hline \multirow{3}{*}{$\operatorname{lnGAP}$} & Direct effect & $-0.350 *(0.164)$ & $-0.570 * * *(0.156)$ & $-0.480 * *(0.162)$ \\
\hline & Indirect effect & $-0.286(0.331)$ & $0.362(0.361)$ & $0.039(0.410)$ \\
\hline & Total effect & $-0.635(0.370)$ & $-0.208(0.397)$ & $-0.441(0.428)$ \\
\hline
\end{tabular}

\subsection{Analysis on education poverty}

As shown in Table 7, the rational ISU had insignificant direct, indirect, or total effect. Therefore, the change of rational ISU does not affect education poverty. The coefficient of $\operatorname{lnHIS}{ }^{\wedge} 2$ was significantly negative, indicating that the advanced ISU has an inverted-U-shaped impact, which echoes with our hypothesis. To be specific, education poverty will intensify in the early phase of ISU; after passing through an inflection point, the continuous ISU will alleviate education poverty. Similar to medical poverty, education poverty changes in an inverted-U-shaped trend, as the siphon effect and growth effect of advanced ISU alternatively occupy the dominant position. Education sector is a traditional industry with stable rate of return. As a result, the siphon effect is obvious in the early phase of ISU, which bottlenecks the development of education; after passing through an inflection point, the growth effect of ISU gradually emerges, and the education sector develops continuously, driven by the accumulated social wealth; the education poverty is thus alleviated in the late phase of ISU. In addition, empirical results show that the alleviation effect only exists in the local 
province, without significant spatial spillover.

Among the control variables, economic development can alleviate education poverty and has spatial spillover effect. The direct effect coefficient of the urban-rural income gap was significantly negative, indicating that a large urban-rural income gap reduces the education poverty in the local province. This seemingly absurd conclusion is not difficult to understand. Faced with high inequality in education, the government will attach too much importance to basic education, and popularize education even at the expense of education quality. However, this will lead to even greater inequality, kicking off a vicious circle. Over the time, a high education penetration will coexist with a large income gap. From the micro-level, rural residents prefer to work in cities and towns when there is a large income gap between rural and urban areas. But jobs in urban areas often raise high requirements on worker quality, forcing them to spend more on education. This indirectly eases education poverty. Nonetheless, this way of alleviating education poverty is not suitable. The increase in education spending inevitably suppresses the expenditures in other fields, and lower the living quality.

\section{CONCLUSIONS}

The following conclusions were drawn on the MDP reduction effect of ISU:

(1) There are significant spatial correlations between income poverty, medical poverty, education poverty, advanced ISU, and rational ISU.

(2) Advanced ISU can effectively alleviate income poverty and medical poverty, mainly through its spatial spillover effect. The advanced ISU has an inverted-U-shaped impact on education poverty; with the continued ISU, education poverty first intensifies, and then eases after passing through an inflection point; however, this impact does not have a significant spatial spillover effect.

(3) Rational ISU exerts a U-shaped impact on income poverty. With the rational ISU, income poverty first decreases to an inflection point, and then increases; but this impact does not have a significant spatial spillover effect. Rational ISU has an inverted-U-shaped effect on medical poverty, without any spatial spillover effect. Rational ISU has no significant effect on education poverty.

Overall, the inverted U-shaped impacts of ISU on education and medical poverties satisfy the proposed hypotheses and meet the laws of mainstream economic theories. However, the U-shaped impact of ISU on income poverty is not as expected. Despite the explanations in the above analysis, further discussion is limited by the lack of data. This "mystery" will be discussed in future research.

\section{ACKNOWLEDGEMENTS}

This work is supported by "Upgrading of Industrial Structure in Guizhou Province under New Structural Economics", a school-level project of Guizhou University of Finance and Economics (Grant No.: 2019XYB14), and "Dynamic Relationship between Foreign Direct Investment, Technological Progress, and Urbanization: An Empirical Analysis Based on Vector Autoregression Model", a student research project of Guizhou University of Finance and Economics (Grant No.: 2019ZXSY38).

\section{REFERENCES}

[1] Samuel, K., Alkire, S., Zavaleta, D., Mills, C., Hammock, J. (2018). Social isolation and its relationship to multidimensional poverty. Oxford Development Studies, 46(1): 83-97. https://doi.org/10.1080/13600818.2017.1311852

[2] Sen, A. (2014). Development as freedom (1999). The globalization and development reader: Perspectives on Development and Global Change, 525.

[3] Feeny, S., McDonald, L. (2016). Vulnerability to multidimensional poverty: Findings from households in Melanesia. The Journal of Development Studies, 52(3): 447-464. https://doi.org/10.1080/00220388.2015.1075974

[4] Lin, Y. (2010). New structural economics: reconstructing the framework of development economics. China Economic Quarterly, 10(1): 1-32. https://doi.org/10.13821/j.cnki.ceq.2011.01.014

[5] Datt, G., Ravallion, M. (1992). Growth and redistribution components of changes in poverty measures: A decomposition with applications to Brazil and India in the 1980s. Journal of Development Economics, 38(2): 275-295. https://doi.org/10.1016/0304-3878(92)90001-P

[6] Thorbecke, E., Jung, H.S. (1996). A multiplier decomposition method to analyze poverty alleviation. Journal of Development Economics, 48(2): 279-300. https://doi.org/10.1016/0304-3878(95)00037-2

[7] Chen, S., Ravallion, M. (2004). China's (uneven) progress against poverty. The World Bank, 82(1): 1-42. https://doi.org/10.1016/j.jdeveco.2005.07.003

[8] Li, X.Y., Yu, L.R., Qi, G.B. (2010). The effect of economic growth on poverty reduction in China from 2000 to 2008: A national and regional empirical analysis. Chinese Rural Economy, 4: 4-11. https://doi.org/10.3724/SP.J.1011.2010.01351

[9] Zhang, F.H., Ye, C.S. (2011). Economic growth, industry structure and rural poverty reduction: based on an empirical analysis of provincial panel data. Contemporary Finance \& Economics, 12: 14-21. https://doi.org/CNKI:SUN:DDCJ.0.2011-12-004

[10] Loayza, N.V., Raddatz, C. (2010). The composition of growth matters for poverty alleviation. Journal of Development Economics, 93(1): 137-151. https://doi.org/10.1016/j.jdeveco.2009.03.008

[11] Ogutu, S.O., Qaim, M. (2019). Commercialization of the small farm sector and multidimensional poverty. World Development, 114: 281-293. https://doi.org/10.1016/j.worlddev.2018.10.012

[12] Bourguignon, F., Chakravarty, S.R. (2019). The measurement of multidimensional poverty. In Poverty, Social Exclusion and Stochastic Dominance, 83-107. https://doi.org/10.1007/978-981-13-3432-0_7

[13] Alkire, S., Apablaza, M., Chakravarty, S., Yalonetzky, G. (2017). Measuring chronic multidimensional poverty. Journal of Policy Modeling, 39(6): 983-1006. https://doi.org/10.1016/j.jpolmod.2017.05.020

[14] Fransman, T., Yu, D. (2019). Multidimensional poverty in South Africa in 2001-16. Development Southern Africa, 36(1): 50-79. https://doi.org/10.1080/0376835X.2018.1469971

[15] Pasha, A. (2017). Regional perspectives on the multidimensional poverty index. World Development, 94:

268-285. 
https://doi.org/10.1016/j.worlddev.2017.01.013

[16] Myrdal, G. (1991). The challenge of world poverty. Beijing: Beijing Institute of Economics Press, 11.

[17] Steele, J.E., Sundsøy, P.R., Pezzulo, C., Alegana, V.A., Bird, T.J., Blumenstock, J., Bjelland, J., Monsen, K.E., de Montjoye, Y.A., Iqbal, A.M., Hadiuzzaman, K.N., Lu, X., Wetter, E., Tatem, A.J., Bengtsson, L. (2017). Mapping poverty using mobile phone and satellite data. Journal of The Royal Society Interface, 14(127): 20160690. https://doi.org/10.1098/rsif.2016.0690

[18] Fu, P., Zhang, P., Zhou, Y. (2018). Spatial agglomeration effect of multidimensional poverty and spatial spillover effect of financial development on poverty reduction: Empirical evidence from China. Journal of Finance and Economics, 44(2):

$115-126$ https://doi.org/10.16538/j.cnki.jfe.2018.02.009

[19] Li, F.C. (2012). The upgrading effect of FDI in home country: an empirical study from China's Provincial Panel. Journal of International Trade, 6: 124-134. https://doi.org/10.13510/j.cnki.jit.2012.06.010

[20] Zou, X. (2018). Age structure, education structure and industrial structure optimization: an analysis of spatial spillover effect based on the provincial level in China. Journal of Hohai University (Philosophy and Social
Sciences), 5: 10. https://doi.org/10.3876/j.issn.16714970.2018.05.009

[21] Padda, I.U.H., Hameed, A. (2018). Estimating multidimensional poverty levels in rural Pakistan: A contribution to sustainable development policies. Journal of Cleaner Production, 197: 435-442. https://doi.org/10.1016/j.jclepro.2018.05.224

[22] Angulo, R., Díaz, Y., Pardo, R. (2016). The Colombian multidimensional poverty index: Measuring poverty in a public policy context. Social Indicators Research, 127(1): 1-38. https://doi.org/10.1007/s11205-015-0964-z

[23] Aguilar, G.R., Sumner, A. (2020). Who are the world's poor? A new profile of global multidimensional poverty. World Development, 126: 104716. https://doi.org/10.1016/j.worlddev.2019.104716

[24] Espinoza-Delgado, J., Klasen, S. (2018). Gender and multidimensional poverty in Nicaragua: An individual based approach. World Development, 110: 466-491. https://doi.org/10.1016/j.worlddev.2018.06.016

[25] Bérenger, V. (2017). Using ordinal variables to measure multidimensional poverty in Egypt and Jordan. The Journal of Economic Inequality, 15(2): 143-173. https://doi.org/10.1007/s10888-017-9349-7 